\title{
Diagnosis of polymyalgia rheumatica in primary health care: favoring and confounding factors - a cohort study
}

\author{
Ciro Manzo ${ }^{1}$, Maria Natale ${ }^{1}$, Enea Traini ${ }^{2}$ \\ ${ }^{1}$ Internal and Geriatric Department, Rheumatologic Outpatient Clinic Hospital “Mariano Lauro”, Sant’Agnello, Italy \\ ${ }^{2}$ Clinical Research, Telemedicine and Telepharmacy Centre, School of Pharmacy, University of Camerino, Camerino, Italy
}

\begin{abstract}
Objectives: To evaluate in a primary care setting the favoring and confounding factors for the diagnosis of polymyalgia rheumatica (PMR).

Material and methods: Among 303 patients consecutively referred by their general practitioners (GPs) to our rheumatologic outpatient clinic, we identified three groups: group A - patients with confirmed diagnosis of PMR, group B - patients with unconfirmed diagnosis, group C - patients with unrecognized PMR. All the diagnostic confounding and favoring factors were discussed with GPs using an e-mail questionnaire. Participation in rheumatology training courses represented the final question. The collected data were statistically assessed in a blind way. In Fisher's exact test and ANOVA test, a p-value was significant if $<0.05$. The study was carried out in compliance with the Helsinki Declaration and approved by the Ethics Committee of Mariano Lauro Hospital. Every patient signed an informed consent form at the time of the first visit.

Results: All patients were Caucasian; $24.1 \%$ were male; mean age was $72.3 \pm 8.6$ years (min. -51 , max. -94). There were 41 patients in group A, 93 in group B and 169 in group C. The percentage of misdiagnoses was very high (87.1\%): among 134 patients diagnosed with PMR by their GPs (group A + group B) confirmation was made in 41, and in 169 unrecognized PMR was found. Participation in training courses was very significant compared to the diagnostic accuracy ( $p<0.0001$ in $\chi^{2}$ test) and to the diagnosis timing ( 24.3 days \pm 12.5 vs. $42.9 \pm 15.5$ with $p$-value $<0.05$ in the ANOVA test). When the percentages were assessed according to participation, an inadequate evaluation of some clinical manifestations favored over-diagnosis among the trained GPS.

Conclusions: The level of diagnostic accuracy for PMR must be improved in primary care. Participation in rheumatology training courses can be an important step.
\end{abstract}

Key words: primary care, polymyalgia rheumatica, rheumatology training courses.

\section{Introduction}

Polymyalgia rheumatica (PMR) is an inflammatory disease which affects people over 50 years old, is more prevalent in females than males, and is predominantly found in the Caucasian ethnic group [1]. Pain in the shoulder and pelvic girdles associated with neck pain and with morning stiffness lasting over 45 minutes are its typical manifestations at onset [2]. Systemic manifestations such as weight loss, fever of unknown origin (FUO), general malaise, and loss of appetite may be present [1, 2]. Many PMR patients are managed by their general practitioners (GPS) and are not referred to rheumatologists [3-5].

\section{Material and methods}

We evaluated 303 patients consecutively referred from January 2010 to March 2016 by their GPs to the 
rheumatologic outpatient clinic of Mariano Lauro Hospital (Sant'Agnello, Italy). In Italy, all citizens are registered with the National Health System of GP Physicians. A specialist visit requires a referral from the GP on which he writes a diagnosis or a suspected diagnosis. With this referral, the patient books the specialist visit through a computerized booking center. Among these 303 patients, we identified three groups: group A - patients with confirmed diagnosis of PMR, group $B$ - patients with an unconfirmed diagnosis, group $\mathrm{C}$ - patients with unrecognized PMR.

We made the diagnosis of PMR according to the criteria proposed by Healey [6]. In a questionnaire sent by e-mail after the first visit, the GP indicated all the elements considered as useful and all those considered confounding for diagnosis. Participation in at least one rheumatology training course in recent years (in which at least one report was about PMR) was the final question. A minimum period of 18 months from the time of the first visit to our outpatient clinic was required to exclude changes in diagnosis. All collected data regarding confirmed cases of PMR were statistically assessed in a blind way by an external expert and analyzed using the SPSS Statistical Package version 20.0 (SPSS Inc, Chicago, IL) with a significance level in Fisher's exact test and ANOVA test of 0.05 .

The study was carried out in compliance with the Helsinki Declaration and was approved by the Ethics Committee of Mariano Lauro Hospital (identification

Table I. Demographic characteristics of studied groups

\begin{tabular}{|c|c|c|c|c|}
\hline Factors & Total & $\begin{array}{c}\text { Group A } \\
\text { PMR confirmed }\end{array}$ & $\begin{array}{c}\text { Group B } \\
\text { PMR not confirmed }\end{array}$ & $\begin{array}{c}\text { Group } C \\
\text { PMR not confirmed }\end{array}$ \\
\hline Number & 303 & 41 & 93 & 169 \\
\hline \multicolumn{5}{|l|}{ Gender } \\
\hline male & 73 (24.1\%) & $14(34.1 \%)$ & $16(17.2 \%)$ & $43(25.4 \%)$ \\
\hline female & $230(75.9 \%)$ & $27(65.9 \%)$ & $77(82.8 \%)$ & $126(74.6 \%)$ \\
\hline \multicolumn{5}{|l|}{ Age } \\
\hline mean $\pm \mathrm{SD}$ & $72.3 \pm 8.6$ & $73.3 \pm 8.2$ & $73.2 \pm 8.7$ & $71.6 \pm 8.6$ \\
\hline $\min$. & 51 & 51 & 52 & 52 \\
\hline $\max$ & 94 & 85 & 94 & 91 \\
\hline
\end{tabular}

PMR - C-reactive protein

A

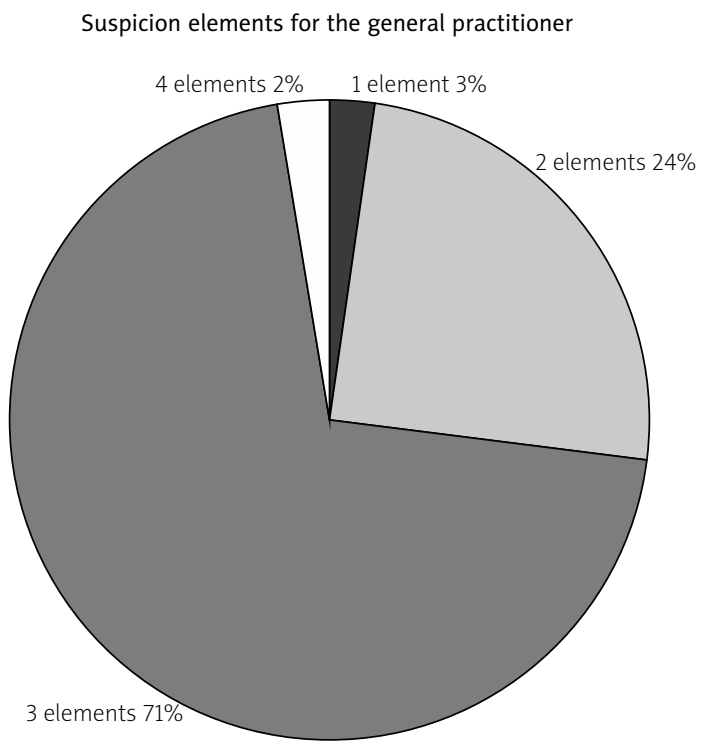

B

Suspicion elements for the general practitioner

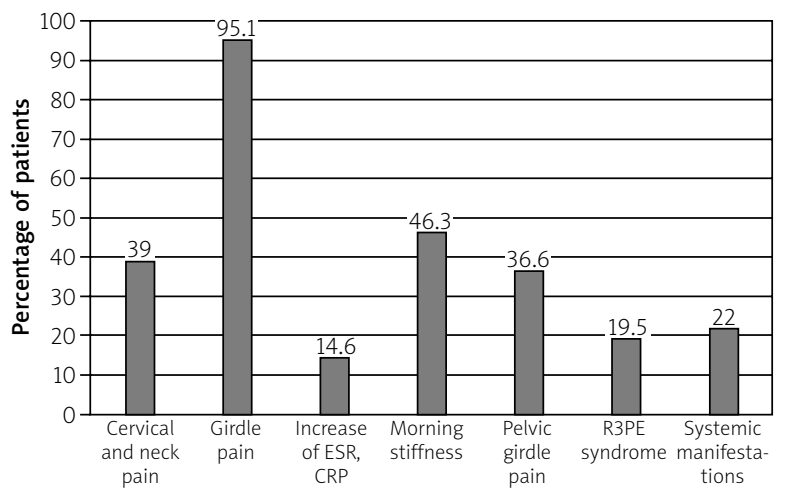

Fig. 1. Group A - polymyalgia rheumatica correctly identified. Suspicion elements for the general practitioner. 
A

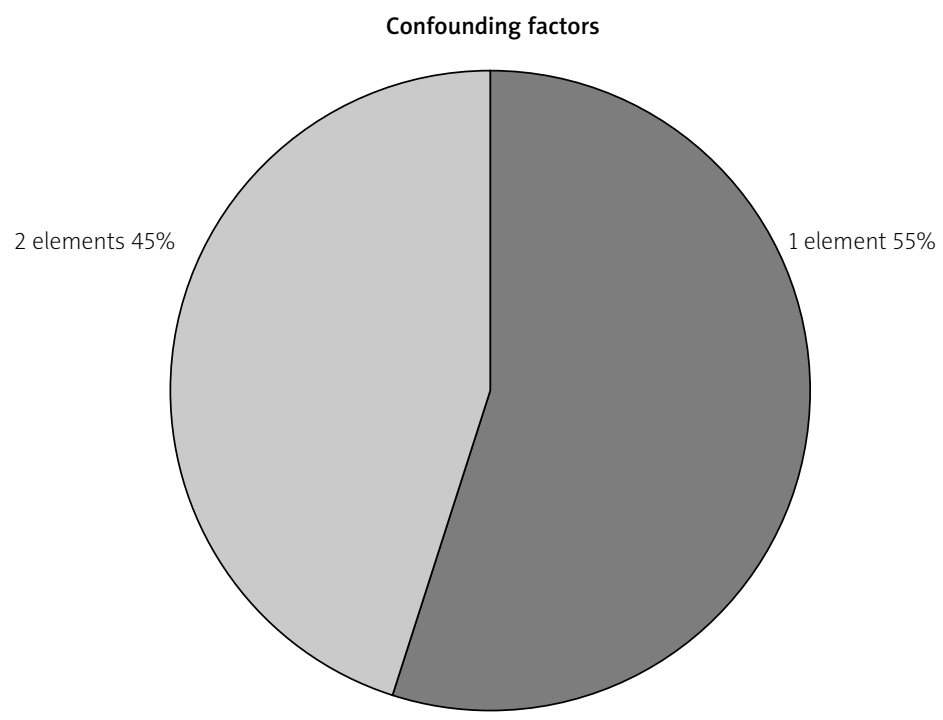

B

Confounding factors

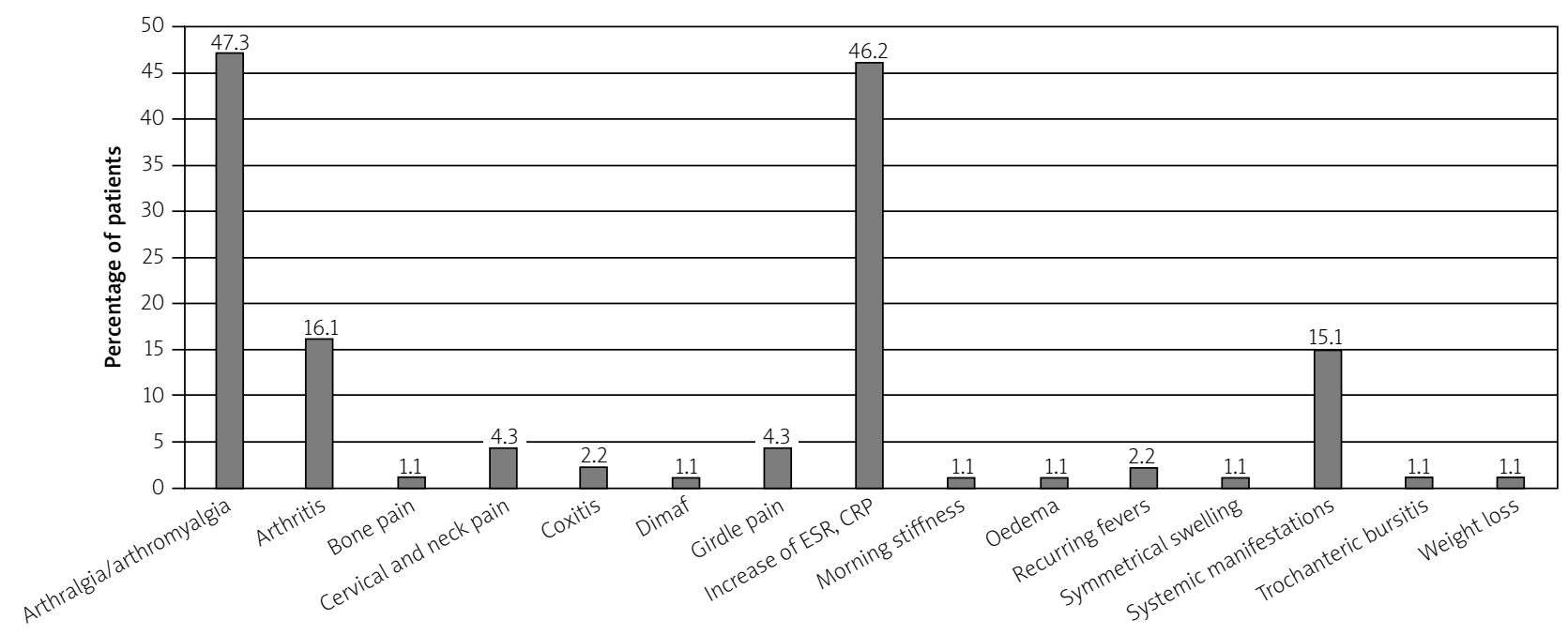

Fig. 2. Group B - incorrect diagnosis of alleged polymyalgia rheumatica and confounding factors.

number: 3/2017). Every patient signed an informed consent form at the time of the first visit.

\section{Results}

All patients were Caucasians. In Table I we present the characteristics of the studied groups in terms of the number of patients, age and gender. We found a very high percentage of misdiagnoses: 93 amongst 134 in groups A + B (69.3\%) as unconfirmed and 169 amongst 210 (81.9\%) as undetected PMR (group C). In particular, in group $A$ there were 3 suspicion elements that GPS considered for a correct diagnosis in $71 \%$ of cases: girdle pain + morning stiffness + cervical and neck pain was the most frequent association. On the other hand, raised erythrocyte sedimentation rate (ESR) and C-reactive protein (CRP) represented a suspicion element in only $14.6 \%$ (Figs. $1 \mathrm{~A}$ and $1 \mathrm{~B}$ ). Remitting seronegative symmetrical synovitis with pitting edema (RS3PE) syndrome represented a suspicion element in a higher percentage (19.5\% in Fig. 1B). In group B the presence of arthralgia (47.3\%) and raised ESR and/or CRP (46.2\%) represented the most frequent confounding elements (Figs. 2A and 2B) and elderly onset rheumatoid arthritis 


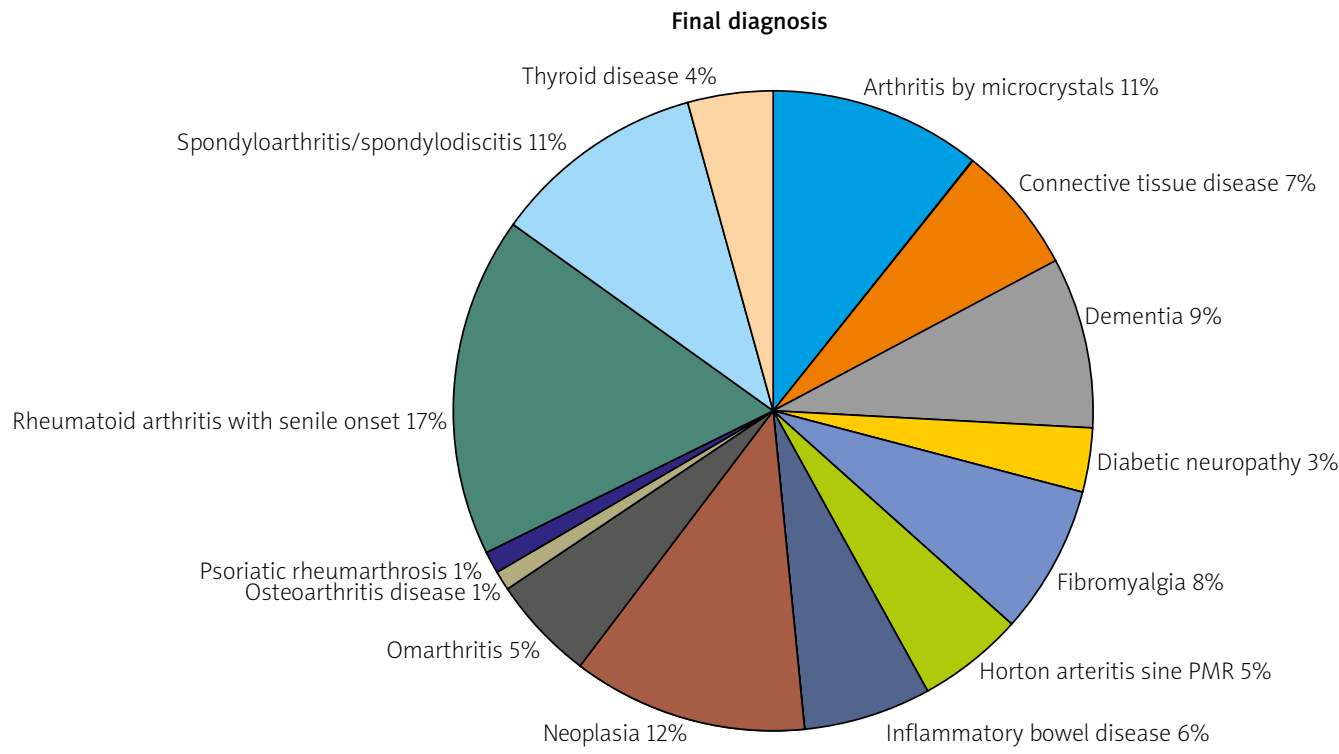

Fig. 3. Group B - incorrect diagnosis of alleged polymyalgia rheumatica and pathologies with which it was confused.

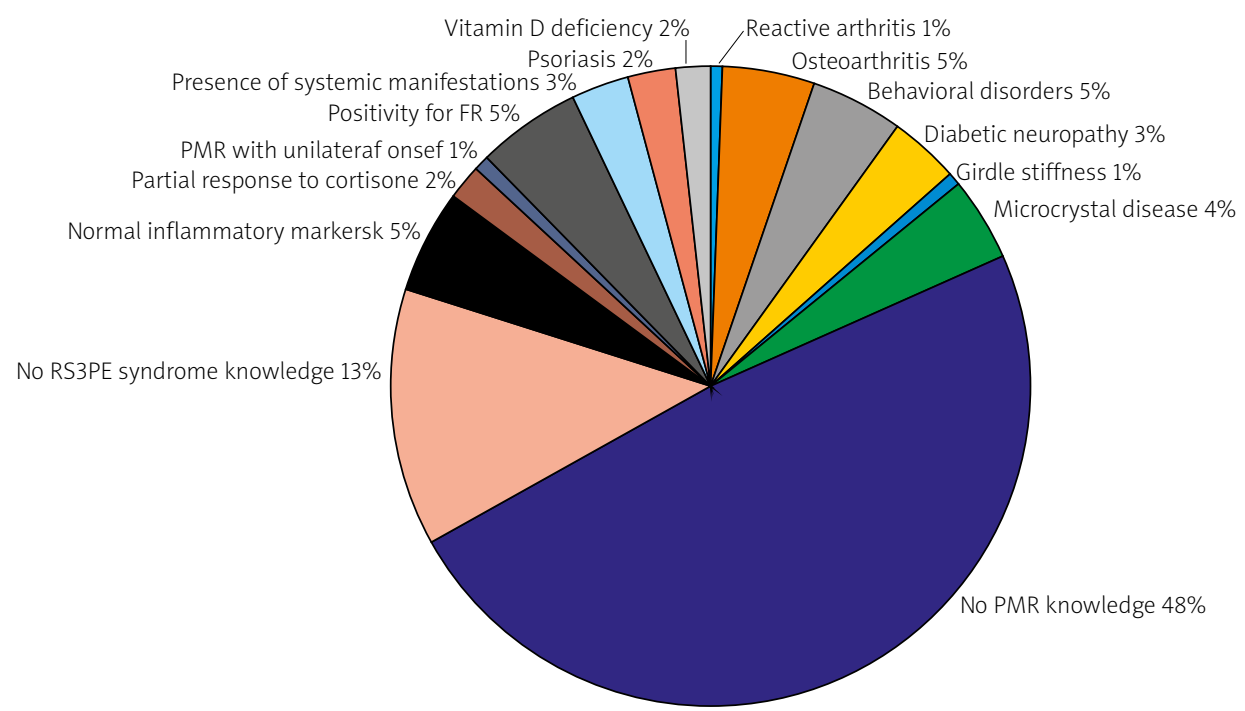

Fig. 4. Group C - confounding factors.

(EORA) was the most confusing disease (17\% in Fig. 3). In the same figure, spondyloarthritis as late onset of undifferentiated spondyloarthritis (SpA) with or without spondylodiscitis, and arthritis caused by crystal deposition (calcium pyrophosphate deposition disease, CPDD) represented $11 \%$ of the diseases with which the PMR was confused.

In group C, the lack of knowledge of PMR was by far the most frequent confounding factor, because $48 \%$ of the GPs did not know about the existence of the PMR (Fig. 4). Systemic manifestations were present in 22\% in group A, in 18.4\% (systemic manifestations + weight loss + FUO) in group B and only in 3\% in group C. When we evaluated how many GPs had participated in recent years in training courses specifically referring to PMR, we found that all the 41 confirmed diagnoses had been made by trained GPs while we found no confirmed diagnosis in the group of the untrained ones (Table II). The association between training and diagnostic accuracy was (evidently) very significant ( $p$-value $<0.0001$ in $\chi^{2}$ test) (Figs. 5A and 5B). Furthermore, in the group of trained GPs the diagnosis time was shorter $(24.3 \pm 12.5$ days) than in the group of untrained ones $(42.9 \pm 15.5$ days), with a $p$-value $<0.05$ in the ANOVA test (Figs. 6A 
A

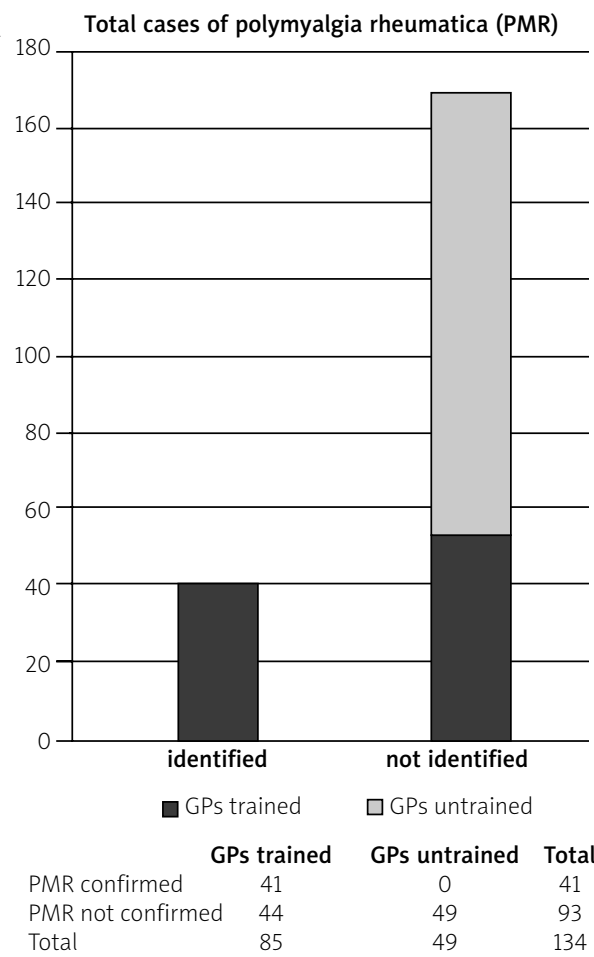

Fisher's exact test

The two-tailed $p$-value $<0.0001$

The association between rows (groups) and columns (outcomes) is considered to be extremely statistically significant

significant difference $p<0.05$ in the $\chi^{2}$ test (Fisher's test)

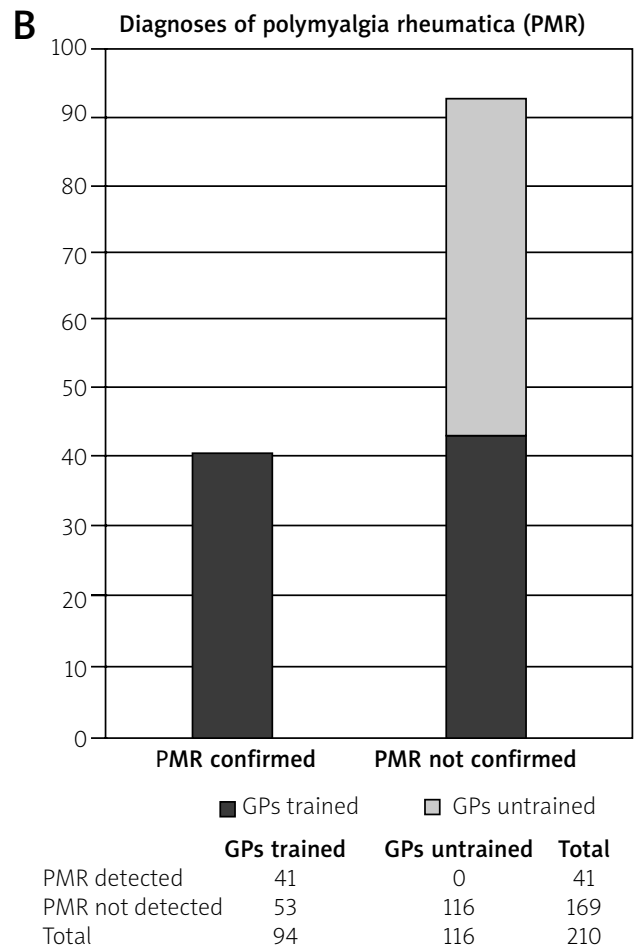

Fisher's exact test

The two-tailed $p$-value $<0.0001$

The association between rows (groups) and columns (outcomes) is considered to be extremely statistically significant

significant difference $p<0.05$ in the $\chi^{2}$ test (Fisher's test)

Fig. 5. (A) Training and diagnosis. (B) Diagnostic time (expressed in days) and its correlation with PMR training.

and 6B). Diagnostic time was calculated as time since first symptoms at correct PMR diagnosis (made by GP and/or outpatient clinic).

On the other hand, when the answers were then assessed according to training or not, an inadequate evaluation of some clinical manifestations (above all, arthralgia, pain in shoulder and pelvic girdles, and neck pain) favored an overdiagnosis among the trained GPs. The systemic manifestations represented confounding factors in $20.4 \%$ of cases among the untrained GPs (Fig. 7 ).

\section{Discussion}

In our cohort study, we found a high percentage of misdiagnosis (262/303; 86.4\%). Several factors were diagnostic confounders and some - as is well known - are diagnostic conundrums even in a rheumatologic setting $[7,8]$. In particular, EORA and PMR have several common points and the differential diagnosis is often very difficult $[9,10]$. Even if some investigators highlighted the possibility that PMR and EORA could be distinguished at baseline $[11,12]$ only the follow-up can confirm the first diagnosis. Therefore, the fact that in our study EORA represented the most confusing disease is not surprising.

Other points are worthy of discussion. As is well known, there is no specific laboratory test for the diagnosis of PMR. An ESR $>40 \mathrm{~mm} / 1^{\text {st }}$ hour is present in all diagnostic criteria proposed in the literature $[1,13]$ even if a sizable proportion (from $7 \%$ up to $22 \%$ ) of PMR patients may have non-raised or slightly raised ESR at the time of diagnosis $[14,15]$. Our data underline that when the GP made a correct clinical examination, the diagnostic mistakes were reduced even if PMR patients had a slightly raised ESR.

In PMR patients, the presence of systemic manifestations strongly favors their hospitalization $[16,17]$. We cannot rule out that some patients with systemic manifestations have been referred to another hospital and not to our ambulatory clinic. This might have resulted in a referral bias especially for group $C$ in which only in $3 \%$ of cases was PMR not recognized due to the presence of systemic manifestations as a confounding element.

RS3PE syndrome represented a suspicion element in $19.5 \%$ in Fig. 1B. As is well known, this syndrome can be 
Diagnostic time (expressed in days)

\begin{tabular}{|lcc|}
\hline & PMR detected by GP & PMR not detected by GP \\
\hline Mean & $24.3 \pm 12.5$ & $42.9 \pm 15.5$ \\
\hline Min. & 3 & 3 \\
\hline Max. & 60 & 87 \\
\hline Median & 22 & 42 \\
\hline
\end{tabular}
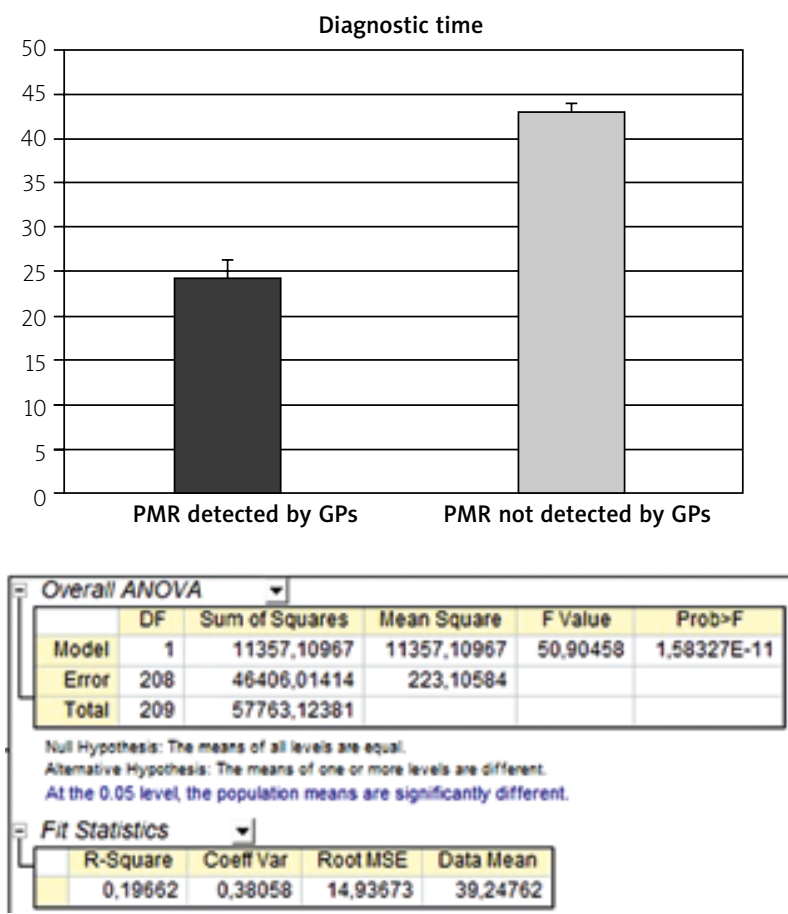

Diagnostic time was calculated as a time since first symptoms at correct PMR diagnosis (made by GP and/or outpatient clinic) Graph represents the mean \pm SEM

Significant difference $p<0.05$ in the ANOVA test

Fig. 6. Diagnostic time (expressed in days) and its correlation with PMR training.

Table II. Relationship between general practitioners' (GPs) training, diagnosis and cases of polymyalgia rheumatica (PMR)

\begin{tabular}{|lccc|}
\hline & Total & GPs trained & GPs untrained \\
\hline GPs & 303 & $138(45.5 \%)$ & $165(54.5 \%)$ \\
\hline Diagnosis of PMR & 134 & $85(63.4 \%)$ & $49(36.6 \%)$ \\
\hline confirmed & 41 & $41(100 \%)^{*}$ & $0(0 \%)$ \\
\hline unconfirmed & 93 & $44(47.3 \%)$ & $49(52.8 \%)$ \\
\hline Cases of PMR & 210 & $94(44.8 \%)$ & $116(55.2 \%)$ \\
\hline detected & 41 & $41(100 \%)^{*}$ & 0 \\
\hline undetected & 169 & $53(31.4 \%)$ & $116(68.6 \%)$ \\
\hline
\end{tabular}

*significant difference $p<0.05$ at the $\chi^{2}$ test (Fischer's test) 


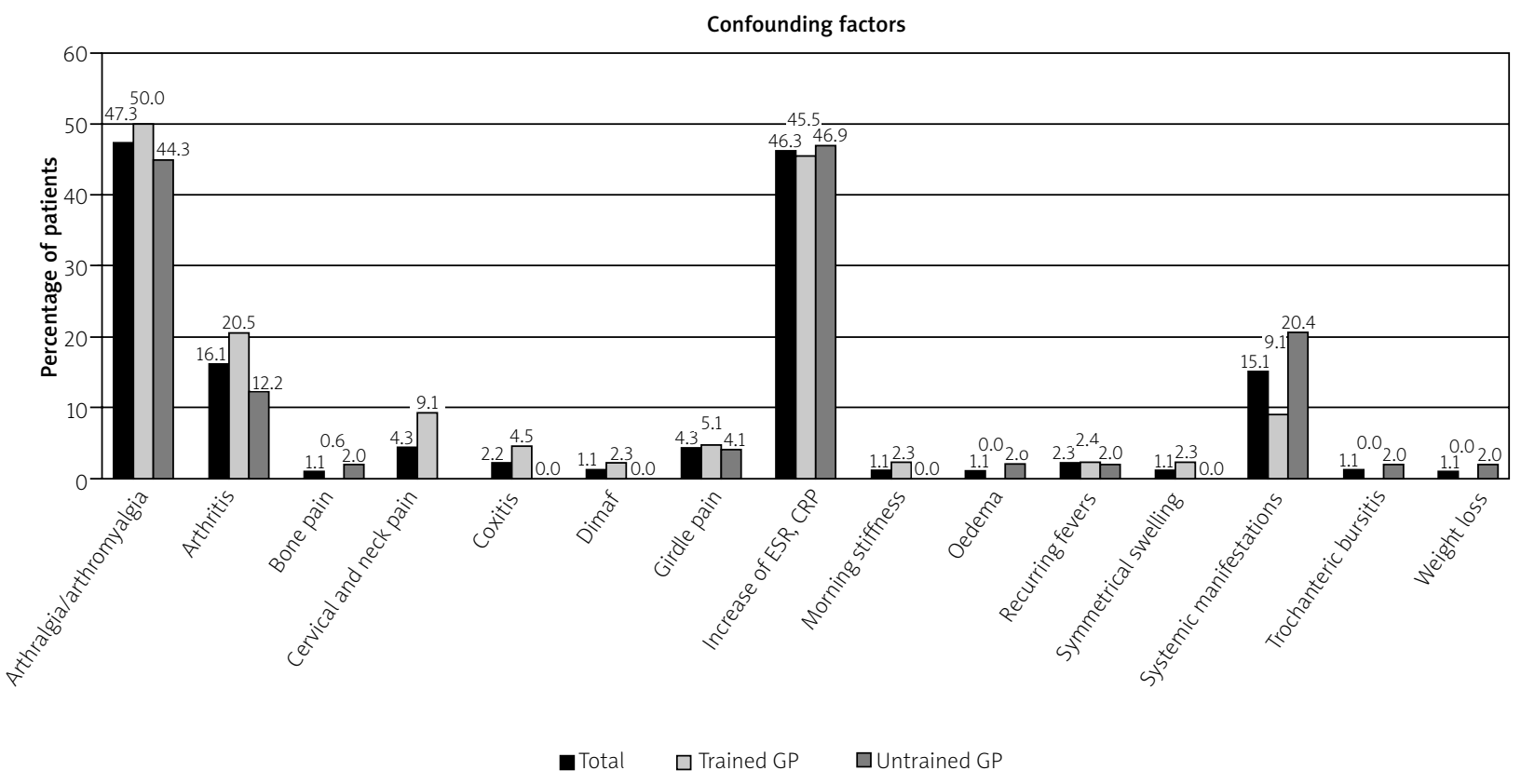

Fig. 7. Group B - percentages of the confounding factors in trained and untrained GPs.

a manifestation of some diseases, especially rheumatic inflammatory diseases. Among these, PMR, RA and SpA are the most frequent [18]. The "boxing-glove" swelling of the hands (and less frequently of the feet) is very suggestive, and we can write that its diagnosis can be easy if we have seen it at least once (even in photography or on a slide). Some investigators believe that RS3PE can be considered an integral part of the spectrum of the PMR manifestations [19] but in no more than $10 \%$ of patients with PMR could we find it. The possibility that PMR associated with RS3PE syndrome may represent a neoplastic warning has been recently highlighted [20, 21]. In our cohort study, RS3PE syndrome represented a suspicion element for PMR in a higher percentage than raised ESR and CRP. These data again emphasize the importance of a correct clinical examination (compared to laboratory data only) and of targeted training.

The percentage of arthritis caused by the deposition of crystals (CPDD, specifically) as confounding diseases (11\% in Fig. 3) is not surprising. In 2005 a Spanish study group coordinated by Pego-Reigosa proposed to include CPDD among the rheumatic diseases with which PMR can be confused [22]. In 1982, Dieppe et al. [23] in a clinical and radiologic study of 105 cases, described 8 patients affected by CPDD associated with PMR and hypothesized that the use of cortisone, associated with a genetic predisposition, could have favored the formation and/or precipitation of calcium pyrophosphate crystals, thereby inducing an overlap between these two pathologies. This possibility must be taken into account in clinical practice. Radiographic (Rx) and an ultrasound (US) evaluation of shoulder and pelvic girdles can reveal the presence of calcifications and favor a correct diagnosis.

In an identical percentage of patients (11\%), PMR was diagnosed whereas they suffered from SpA (Fig. 3). The possibility that PMR at onset may mask a late onset of undifferentiated spondylarthritis has been more and more often described [24-26]. In these patients, a correct diagnosis is usually possible if we consider the entire clinical spectrum of features of spondyloarthritis and not only the PMR-like manifestations.

As highlighted in our introduction, many patients with PMR are evaluated and treated in the setting of "family medicine" and are not referred to secondary or tertiary care. In a study from the UK only $44.4 \%$ of patients with PMR underwent specialist consultant evaluation [27]; in another study, this percentage dropped to $17 \%$, and there is a need to refer to secondary care if there are atypical features or a suboptimal response to treatment for further assessment [28].

In the literature, the level of diagnostic accuracy and appropriateness for PMR by the GPS is low in all the reports $[2,3,29,30]$. It is evident that studies based on uncontrolled databases can determine significant epidemiological mistakes, and this point must be well considered [31]. Participation in targeted training courses can represent a useful collaboration between primary and secondary care, even taking into account that an excess of diagnosis among trained GPs is possible.

Our study had some limitations. Firstly, it reflects the organization of the Italian health system. In Italy, for example, the presence of a professional figure represent- 
ed by the out-of-hospital public specialist (specifically, an out-of-hospital public rheumatologist) introduces an element of substantial differentiation with the recognition of a dividing line between GPs and centers of the second or third level, totally absent in almost all other nations.

On the other hand, in Italy there is not a primary care research protocol such as - for example - the "PMR cohort study" proposed since 2012 in England [32]. Cohort studies performed in other countries (including Poland) with different healthcare organizations could lead to different conclusions.

Secondly, the high number of over-diagnosed PMR suggested that in primary care a lot of persons could be under GC therapy without utility. Unfortunately the design of our study did not propose an analysis of the therapeutic approach, and this may represent another limitation.

Lastly, we cannot rule out that a referral bias may be present. Certainly, the number of patients sent to our outpatient clinic by some GPs was very low, and we cannot exclude that patients with PMR and systemic manifestations may have been hospitalized directly, without going through our ambulatory clinic.

\section{Conclusions}

PMR is a disease mainly managed in primary care, but the level of the GP's diagnostic accuracy is often low, as confirmed by our cohort study. It is possible to improve this situation with more formalized collaboration between primary and secondary care. Targeted training courses represent an example of collaboration that should be emphasized.

The authors declare no conflict of interest.

\section{References}

1. González-Gay MA, Matteson EL, Castan̈eda S. Polymyalgia rheumatica. Lancet 2017; 390: 1700-1712.

2. Buttgereit F, Dejaco C, Matteson EL, et al. Polymyalgia Rheumatica and Giant Cell Arteritis. JAMA 2016; 315: 2442-2458.

3. Helliwell T, Hider SL, Mallen CD. Polymyalgia rheumatica: diagnosis, prescribing and monitoring in general practice. $\mathrm{Br}$ J Gen Pract 2013; 63: e361-366.

4. Mathew R, Rashid A. Polymyalgia rheumatica in primary care: managing diagnostic uncertainty. BMJ 2015; 351: h5199.

5. Manzo C, Balduccelli M, Cappiello F, et al. Prevalence and incidence of polymyalgia rheumatica in Massa Lubrense, Italy. Trends Med 2009; 9: 85-89.

6. Healey LA. Long-term follow-up of polymyalgia rheumatica: evidence of synovitis. Semin Arthritis Rheum 1984; 13: 322328.
7. Ceccato F, Uña C, Regidor M, et al. Conditions mimicking polymyalgia rheumatica. Reumatol Clin 2011; 7: 156-160.

8. Manzo C, Camellino D. La polimialgia reumatica: difficoltà diagnostiche e terapeutiche per una malattia apparentemente "banale". Recenti Prog Med 2017; 108: 221-231.

9. Healey LA. Polymyalgia rheumatica and seronegative rheumatoid arthritis may be the same entity. J Rheumatol 1992; 19: 270-272.

10. Olivo D, D'Amore M, Mattace-Raso F, et al. Clinical and laboratory features at onset of polymyalgia rheumatica (PMR) and elderly onset of rheumatoid arthritis in PMR-like presentation: a comparison of two groups of patients. Arch Gerontol Geriatr 1996; 22 suppl 1: 527-533.

11. Pease CT, Haugeberg G, Montague B, et al. Polymyalgia rheumatica can be distinguished from late onset rheumatoid arthritis at baseline: results of a 5-yr prospective study. Rheumatology 2009; 48: 123-127.

12. Caporali R, Montecucco C, Epis O, et al. Presenting features of polymyalgia rheumatica (PMR) and rheumatoid arthritis with PMR-like onset: a prospective study. Ann Rheum Dis 2001; 60: 1021-1024

13. Bird HA, Esselinckx W, Dixon AS, et al. An evaluation of criteria for polymyalgia rheumatica. Ann Rheum Dis 1979; 38: 434-439.

14. Ellis ME, Ralston S. The ESR in the diagnosis and management of the polymyalgia rheumatica/giant cell arteritis syndrome. Ann Rheum Dis 1983; 42: 168-170.

15. Proven A, Gabriel SE, Fallon WM, Hunder GG. Polymyalgia rheumatica with low erythrocyte sedimentation rate at diagnosis. J Rheumatol 1999; 26: 1333-1337.

16. Dalkılıç E, Tufan AN, Hafızoğlu E, et al. The process from symptom onset to rheumatology clinic in polymyalgia rheumatica. Rheumatol Int 2014; 34: 1589-1592.

17. Manzo C, Natale M. Polymyalgia rheumatica and cancer risk: the importance of the diagnostic set. Open Access Rheumatol 2016; 8: 93-95.

18. Manzo C, Stisi S. La sindrome RS3PE: tre cose utili da ricordare per il geriatra. GerExtraosp 2016; XI: 23-25.

19. Salvarani C, Gabriel S, Hunder GG. Distal extremity swelling with pitting edema in polymyalgia rheumatica: Report of nineteen cases. Arthritis Rheum 1996; 39: 73-80.

20. Manzo C. The paraneoplastic meaning of R3SPE (remitting seronegative simmetrical synovitis with pitting edema) syndrome. J Med Oncl Ther 2016; 1: 72-75

21. Manzo C, Natale M. Polymyalgia Rheumatica in Association with Remitting Seronegative Sinovitis with Pitting Edema: a Neoplastic Warning. Can Geriatr J 2017; 20: 94-96.

22. Pego-Reigosa JM, Rodriguez-Rodriguez M, Hurtado-Hernandez Z, et al. Calcium pyrophosphate deposition disease mimicking polymyalgia rheumatica: a prospective followup study of predictive factors for this condition in patients presenting with polymyalgia symptoms. Arthritis Rheum 2005; 53: 931938.

23. Dieppe PA, Alexander GJ, Jones HE, et al. Pyrophosphate arthropathy: a clinical and radiological study of 105 cases. Ann Rheum Dis 1982; 41: 371-376.

24. Olivieri I, Garcia-Porrua C, Padula A, et al. Late onset undifferentiated spondyloarthritis presenting with polymyalgia 
rheumatica features: description of seven cases. Rheumatol Int 2007; 27: 927-933.

25. Aydeniz A, Altındağ $\mathrm{O}$, Oğüt $\mathrm{E}$, et al. Late onset spondyloarthropathy mimicking polymyalgia rheumatica. Rheumatol Int 2012; 32: 1357-1358.

26. Kouassi Djaha J-M, Jenvrin C, Dupont M-P, et al. Late onset spondyloarthropathy misdiagnosed as polymyalgia rheumatica. Rev Med Interne 2013; 34: 667-670.

27. Yates M, Graham K, Watts RA, MacGregor AJ. The prevalence of giant cell arteritis and polymyalgia rheumatica in a UK primary care population. BMC Musculoskelet Disord 2016; 17 : 285.

28. Barraclough K, Liddell WG, du Toit J, et al. Polymyalgia rheumatica in primary care: a cohort study of the diagnostic criteria and outcome. Fam Pract 2008; 25: 328-333.

29. Quick V, Kirwan JR. Our approach to the diagnosis and treatment of polymyalgia rheumatica and giant cell (temporal) arteritis. J R Coll Physicians Edinb 2012; 42: 341-349.

30. Yates M, Graham K, Watts RA, MacGregor AJ. The prevalence of giant cell arteritis and polymyalgia rheumatica in a UK primary care population. BMC Musculoskelet Disord 2016; 17: 285.

31. Rooney PJ, Rooney J, Balint G, et al. Polymyalgia rheumatica: 125 years of epidemiological progress? Scottish Med J 2015; 60: 50-57.

32. Muller S, Hider S, Helliwell T, et al. The epidemiology of polymyalgia rheumatica in primary care: a research protocol. BMC Musculoskelet Disord 2012; 13: 102. 